\title{
O Uso do Apoio Matricial como Dispositivo de Clínica Ampliada em Saúde Bucal: Revisão das Experiências Documentadas na Literatura Científica
}

\author{
Carnut, Leonardo; Barros, Allan Vinícius M. de; Oliveira, Márcia Rosana Farias; \\ Oliveira, Mylena Rafhaele G. de; Júnior, Luiz Gutenberg T. M. C.; Correia, Tereza \\ Cristina; Lyra, Arine \\ Universidade de Pernambuco — leonardo.carnut@upe.br
}

\begin{abstract}
Introdução: Cotidianamente, a responsabilidade dos profissionais pelos usuários no SUS não vem ultrapassando a mera disponibilidade do espaço físico. em serviços de primeiro contato, como no caso da atenção básica, o envolvimento dos profissionais de saúde com os usuários é fundamental e sua ausência prejudica substancialmente a integralidade na atenção. Objetivo: Assim, este estudo revisou a literatura pertinente às experiências do uso do Apoio Matricial e Equipes de Referência no âmbito da Atenção Básica à Saúde, evidenciando os desafios e obstáculos encontrados durante a implantação da Clínica Ampliada com intuito de fomentar o debate no que tange às práticas de saúde bucal na Estratégia de Saúde da Família. Método: para elaboração da revisão recorreu-se ao banco de dados BVS (Biblioteca Virtual de Saúde) e as bases de dados Literatura Latino-Americana em Ciências da Saúde - LILACS e Scientific Eletronic Library Online - SCIELO. Através do uso de descritores de assunto relacionados ao tema e, dos operadores booleanos além da leitura critica dos resumos de artigos encontrados, foi realizada a seleção dos artigos. dos dois artigos considerados de maior relevância para o estudo foram eleitos apenas dois tratavam diretamente do tema da revisão. Resultados: Os artigos escolhidos continham relatos de experiência de profissionais que participaram da experiência de implantação do apoio matricial na estratégia de saúde da família. Segundo os relatos das experiências, o Apoio Matricial conseguiu assegurar retaguarda especializada do tipo assistencial a profissionais encarregados da atenção a problemas de saúde, que constituem as Equipes de Referência, de maneira personalizada e interativa, compondo, desse modo, uma equipe interprofissional e interdisciplinar a qual se envolve com a saúde dos usuários de forma integral. a função do apoiador matricial se assemelha a um agregador de recursos de saber que contribui com intervenções que aumentem a capacidade de resolutiva de equipes primariamente responsáveis. Essa inovação gerencial é de suma importância como dispositivos da Clínica Ampliada, pois promove uma reorganização dos serviços de saúde através de novos arranjos organizacionais transversais que ampliam a capacidade de lidar com as singularidades dos sujeitos. Conclusão: Conclui-se que os estudos sobre tema são raros e essa lacuna existente indica a necessidade de esforços de pesquisa dirigidos ao local da equipe de saúde bucal em práticas de clínica ampliada segundo dispositivos de apoio matricial.
\end{abstract}

Carnut, Leonardo; Barros, Allan Vinícius M. de; Oliveira, Márcia Rosana Farias; Oliveira, Mylena Rafhaele G. de; Júnior, Luiz Gutenberg T. M. C.; Correia, Tereza Cristina; Lyra, Arine. O Uso do Apoio Matricial como Dispositivo de Clínica Ampliada em Saúde Bucal: Revisão das Experiências Documentadas na Literatura Científica. In: Anais do Congresso Internacional de Humanidades \& Humanização em Saúde [= Blucher Medical Proceedings, num.2, vol.1]. São Paulo: Editora Blucher, 2014. ISSN 2357-7282

DOI 10.5151/medpro-cihhs-10207 